\title{
Cuando el resentimiento se vuelve un imperativo ético. Reflexiones en torno a Jean Améry.
}

\author{
When resentment becomes an ethical imperative. Reflections \\ on Jean Amery
}

\section{Roberto Israel Rodríguez Soriano}

Instituto de Educación Media Superior CDMX / Universidad Autónoma del Estado de Morelos (MÉXICO)

CE: calla_o@yahoo.com.mx / roberto.i.soriano@gmail.com / ID ORCID: 0000-0002-7088-103X

DOI: $10.32870 /$ sincronia.axxiv.n77.6a20

Esta obra está bajo una Licencia Creative Commons Atribución-NoComercial 4.0 Internacional $\mathrm{BY} \cdot \mathrm{NC}$

Recibido: $25 / 07 / 2019$

Revisado: $18 / 10 / 2019$

Aprobado: 02/12/2019

\section{RESUMEN}

Jean Améry, sobreviviente del campo de extermino de Auschwitz, en su libro Más allá de la culpa y la expiación (1966) plantea que hay una irreductibilidad teórico-conceptual de la experiencia subjetiva de la víctima de un crimen. Su propuesta va contra la filosofía moral de Nietzsche y el psicoanálisis freudiano.

En este trabajo se ofrecerá, a partir de la lectura de la obra referida, un análisis de la propuesta de Jean Amerý sobre la categoría de "resentimiento".

Éste se vuelve el motor de una demanda que exige justicia contra el crimen cometido. Así, se vuelve un imperativo ético que denuncia la imposibilidad de una convivencia intersubjetiva hasta que haya justicia a la víctima y dicha justicia debe concretarse en el sentimiento y la necesidad de resarcimiento. 
Palabras clave: Resentimiento. Moral. Progreso. Justicia. Víctima. Psicoanálisis. Trauma. Auschwitz. Memoria. Olvido.

\section{ABSTRACT}

Jean Améry, a survivor of the Auschwitz extermination camp, in his book Beyond Guilt and Atonement (1966) argues that there is a theoretical-conceptual irreducibility of the subjective experience of the victim of a crime. His proposal goes against the moral philosophy of Nietzsche and Freudian psychoanalysis.

In this work, analysis of Jean Amery's proposal on the category of "resentment" will be offered from the reading of the referred work.

The "resentment" becomes the motor of a lawsuit demanding justice against the crime committed. Thus, it becomes an ethical imperative that denounces the impossibility of an intersubjective coexistence until there is justice to the victim and that justice must be concretized in the feeling and the need for compensation. This imperative is against the concept of justice that seeks to overcome crime based on forgetfulness that forces reconciliation between victim and victimizer.

Keywords: Resentment. Moral. Progress. Justice. Victim. Psychoanalysis. Trauma. Auschwitz. Memory. Forgetfulness.

Para que algo permanezca en la memoria se lo graba a fuego; sólo lo que no cesa de doler permanece en la memoria.

(Nietzsche, 2006, p. 79)

\section{Introducción}

Emmanuel Kant intentó fundamentar de manera objetiva ${ }^{1}$ el acto ético. En su teoría, éste se intentaba cimentar en el principio de autonomía. Para él, la razón adquiría el papel primordial de

\footnotetext{
${ }^{1}$ Kant en la Metafísica de las Costumbres hace un rechazo a una moral fundamentada empíricamente, así como un rechazo a una ética de fines al modo del utilitarismo supone. Por un lado, critica el que la significación moral sea
} 
ser rectora de la voluntad para generar una voluntad buena en sí misma y no como medio a otro propósito. La razón desempeña la función de dirigir, en su cualidad de capacidad práctica, a la voluntad como buen supremo y como condición de cualquier otro bien. Así, la razón desempeña la función del deber. Para Kant la razón humana tiene, a priori, las determinaciones del acto que tienden hacia la corrección del acto bueno. Sólo el ser humano tiene la capacidad de obrar según las representaciones de la ley, porque posee voluntad. Ésta, por lo anterior, es una razón práctica (Kant, 1991, 91).

La modernidad le ha apostado a esta fundamentación del acto ético. Una fundamentación que parte de un principio racional. Sin embargo, los sucesos históricos han mostrado que cuando los principios éticos se fundamentan puramente en la autonomía como único principio, las consecuencias de los actos pueden ser catastróficas. Aquí baste apuntar el caso de Adolf Eichmman a partir del cual Hannah Arendt lo conceptualiza en la "banalidad del mal" (hombres normales realizan atrocidades bajo el mandato autónomo) (Arendt, 2009, 402).

Entonces, la fundamentación del acto ético debe partir de la subjetividad contra la objetividad de la razón. La objetividad se debe entender como des-subjetivación, es decir, como una eliminación del elemento experiencial y de emotividad de una vivencia o de la motivación de un acto ético. Contra esta perspectiva de fundamentación ética se encuentra el resentimiento.

Dice:

Hay aspectos de la realidad que únicamente se perciben si hay un cambio de actitud en los ojos que los miran. En esta línea epistemológica está el refrán de la sabiduría africana cuando dice que "hay cosas que sólo se ven tas haber llorado». El sufrimiento proporciona así una actitud y un sesgo en la mirada que propicia el descubrimiento de aspectos de la realidad que de otra manera quedarían ocultos.

\footnotetext{
determinada por los efectos del acto; por otro lado, critica el que se fie un fin supremo, tales como la felicidad o el pacer, para determinar el valor del acto moral. En ambos casos se está prescindiendo de propósitos y se está soportando en los fines. La teoría ética kantiana supone una teología del acto ético. Dentro de ésta el acto moral persigue un valor, el valor máximo, el valor de la humanidad. Se debe actuar de acuerdo con éste, de manera que el actuar por deber es actuar de tal manera que las acciones expresen el valor de la humanidad (Kant, 1991, p. 67).
} 
Aplicado a una política emancipatoria, en cuanto preocupación y cuidado por la vida de os hombres en la sociedad ayuda a ver mejor los problemas de la sociedad. (...) El sufrimiento es un educador de la vista: nos ayuda a fijar los ojos en el dolor de esta sociedad y así nos descubre lo que habitualmente no se ve.

La solidaridad en el sufrimiento es también un educador del corazón (Mardones, 2004, 53-54).

Entonces, la fundamentación del acto ético debe partir de la subjetividad contra la objetividad de la razón. La objetividad se debe entender como des-subjetivación, es decir como una eliminación del elemento experiencial y de emotividad de una vivencia o de la motivación de un acto ético. Bajo esta perspectiva de fundamentación ética se encuentra el resentimiento.

Se lee en el diccionario de psicología que el resentimiento es una

[...] aversión y un odio a todo aquello que no se puede ser o no se puede tener. Por su vinculación a un profundo sentimiento de impotencia que anula todo [sic] posibilidad de represalia, el resentimiento no logra traducirse en venganza, pero puede crear, como pensaba F. Nietzsche a propósito de la "moral del resentimiento", valores individuales y colectivos en los que se expresa la venganza imaginaria de los resentidos. (Galibert, 2002, p. 964).

El resentimiento es caracterizado, a partir de una valoración moral, como un sentimiento negativo (odio, aversión y envidia) que origina un sentido de impotencia y que afecta profundamente el comportamiento del individuo y de una sociedad en la medida en que existe la imposibilidad del cumplimiento de un deseo. La valoración axiológica del resentimiento es negativa y los ideales culturales buscan, por muchos y diversos medios, condenarlo enfatizando su negatividad y destructividad para la cohesión social y para la salud individual y social; así como generar múltiples formas prácticas y teóricas que permitan eliminarlo o marginarlo. Sin embargo, a contracorriente de estas valoraciones culturales, el resentimiento de lado de la víctima de un crimen adquiere la potencialidad de una demanda ética que, justamente, puede, en una exigencia de justicia, cimentar 
las bases para el surgimiento de una forma de convivencia basada en el cumplimiento de esa justicia.

En Más allá de la culpa y la expiación (1966) de Jean Améry, sobreviviente del campo de extermino de Auschwitz ${ }^{2}$ plantea que hay una irreductibilidad teórico-conceptual (sobre todo con fines morales o psicológicos) de la experiencia subjetiva de la víctima de un crimen. Esa irreductibilidad pertenece a un estrato primario, único e inaccesible de la experiencia de la víctima. De ese estrato se soporta la legitimidad de una demanda ética que busca resarcir de alguna forma el daño de la vejación sufrida. Como lo ha señalado Pablo Drews, el resentimiento para Améry "fue el único aliciente para conservar su humanidad, su validez moral y su validez histórica" (Drews, 2012, s.p.).

La experiencia vivencial se resiste a la conceptualización porque esta última desgarra la materialidad de la experiencia vivida. Améry con esa experiencia subjetiva se rebela contra la metafísica (filosófica y psicológica); se rebela contra la superchería de la metafísica de la palabra y del concepto que se quieren hacer pasar por objetivas, y contra las realidades que éstos crean. Lo

2 Jean Améry (Hans Maier) nació en 1912 en Viena en el seno de una familia judía. En 1933 comenzó sus estudios en la escuela de comercio librero. En la década de los 30's asiste a clases de filosofía impartidas por algunos de los miembros fundadores del Círculo de Viena. A los 21 años se casó con Regine Berger-Baumgarten. En 1934 se adhirió al movimiento de la revolución obrera austriaca colaborando en el transporte clandestino de armas destinadas a los huelguistas comunistas. Ante el peligro inminente de la promulgación de las leyes raciales de Nüremberg y el sistemático arresto de judíos inició una fuga entre 1938 y 1938 por varias ciudades de Austria. Trabajó como profesor de idiomas hasta 1940 cuando las tropas alemanas invaden Bélgica. Fue arrestado el 10 de mayo e internado en el Lager de Mechelen. Fue deportado al campo de Saint-Cyprien en los Pirineos. El 26 de julio de ese mismo año fue entregado a las tropas alemanas y el 29 de julio es internado en el campo francés de Gurs. El 6 de lulio de 1941 se fugó de dicho campo por París y atraviesa Francia que estaba ocupada por los alemanes. Se unió al movimiento de la Resistencia belga que se dedicaba a distribuir propaganda antinazi en la ocupación alemana. Trabajó como profesor de idiomas en el École Moyenne Juive de Bruxellles. El 23 de julio de 1943 fue detenido por repartir pasquines y fue enviado al cuartel de la Gestapo en Bruselas. Fue ingresado al campo de acogida de Breendonk en Ambers. Fue torturado por las SS. El 15 de enero fue deportado a Auschwitz. Entre el 17 de abril y el 26 de enero comenzó la evacuación de prisioneros del Lager, en marchas a pie, de Auschwitz-Monowitz a Gleiwitz II, y de ahí en tren hacia Sajonia. Entre el 1ํ y el 4 de febrero llegó al campo de Mittelbau. Un mes después fue evacuado hacia Bergen-Belsen. El 15 de abril las tropas británicas liberaron el campo de Bergen-Belsen. En ese año Améry retornó a Bruselas. Con el seudónimo de Hanns Mayer escribió artículos en periódicos holandeses y suizos. En 1955 trabajó como corresponsal en Londres y adoptó el seudónimo de Jean Améry. Se suicidó el 17 de octubre de 1978. 
decible y lo expresable tienen su límite y posibilidad en el umbral del dolor y del sufrimiento de la víctima:

Sólo yo estaba, y estoy en posesión de la verdad moral de los golpes que aún hoy me resuenan en el cráneo y, por tanto, me siento más legitimado a juzgar, no sólo respecto a los ejecutores, sino también a la sociedad que sólo piensa en su supervivencia. (2004, p. 151).

El alegato de Améry es contra la injusticia y la absolución del criminal; es contra el olvido que hace posible esto. Es una afirmación de lo más primario y elemental que le queda a la víctima: su subjetividad, y sus sentimientos y emociones que se gestan en ésta.

En la obra hay una paradoja que se produce porque las descripciones y testimonios que él ofrece en su libro generan vetas para atisbos de conocimiento y comprensión del crimen incomprensible cometido contra él y millones de personas. Entonces ¿cómo debe ser leído el texto de Améry? ¿debe ser leído como un testimonio de un sobreviviente de Auschwitz? ¿ante qué se encuentra el lector? Parece que el testimonio de Améry adquiere sentido y relevancia especial dentro del sentimiento que dicho acontecimiento le origina. Es decir, el testimonio no puede ser leído a espaldas del sentimiento de las emociones que motivan el relato: no debe ser leído a espaladas del resentimiento. Entonces, no es una narración histórica per se; no es una narración didáctica. Améry hace una narración de lo que vivió en los campos de exterminio nazi en la medida en que describen su resentimiento. Éste no requiere una justificación extrínseca a la subjetividad de su experiencia. No requiere de una explicación o comprensión científica, literaria, psicológica o moralina. Requerirle dicha justificación sería banalizar su vivencia y el rencor que viene con ésta.

El resentimiento se vuelve el motor de una demanda que exige justicia contra el crimen cometido. Así, se vuelve un imperativo ético que denuncia la imposibilidad de una convivencia intersubjetiva hasta que haya justicia a la víctima y dicha justicia debe concretarse en el sentimiento y en la necesidad de resarcimiento de la víctima. Éste se vuelve un imperativo ético contra el 
concepto de justicia que busca la superación del crimen con base en el olvido que fuerce la reconciliación entre víctima y victimario.

La justicia no es una restitución. ¿Cómo se puede restituir lo irrestituible? La justicia no es venganza. La justicia no es la expiación. La justicia más bien es el reconocimiento y asunción de la responsabilidad por parte del victimario y de sus cómplices del crimen que cometieron:

Mi resentimiento existe con el objeto de que el delito adquiera realidad moral para el criminal, con el objeto de que se vea obligado a enfrentar la verdad de su crimen. (...) la cuestión no estriba en si he escudriñado a fondo en mi fuero interno, no consiste ni en la venganza no tampoco en la expiación. (...) Lo que me importa es redimirme de un desamparo que aún perdura desde entonces (Améry, 2004, p. 151).

Así, la justicia se vuelve algo subjetivo que remite a la relación intersubjetiva entre víctima y victimario en la que se pone de trasfondo, y les exige justicia de la misma forma, a las dimensiones históricas y sociales que posibilitaron el crimen. Dice Julián Marrades:

Éste es el sentido de su exigencia [de Améry] de traer al presente lo sucedido entre ambos mediante una comparecencia del verdugo antes su crimen, que no puede darse sólo en un plano individual-moral, sino que ha de plantearse en el ámbito de la praxis colectiva e histórica en que ocurrió el crimen (2004, p. 229).

Como primera parte de este escrito haré una breve referencia de la concepción nietzscheana sobre el resentimiento con el fin identificar algunos de los supuestos contra los que contraarguenta Améry. La lectura nietzscheana sobre la moral ha tenido gran impacto en el pensamiento occidental, tanto en su metodología genealógica como en su interpretación filológica. Uno de los impactos (directos o indirectos), que parece insoslayable, fue sobre la ideología nacionalsocialista y su rabioso antisemitismo, así como en la filosofía moral a lo largo del siglo XX y lo que va del XXI.

Como otro apartado de esta primera sección del trabajo ofrezco una lectura de algunos de los supuestos teóricos que desarrolla el psicoanálisis freudiano sobre la cuestión del resentimiento. Esto con la intención de recuperar algunos de los puntos de concordancia y discordancia de éstos 
con la apelación de Améry, en la medida en que la explicación psicológica sobre el resentimiento es uno de sus referentes de discusión.

Como segunda parte del trabajo ofrezco una lectura sobre el resentimiento en la exposición de Améry. Esta lectura es complementada con algunas implicaciones que tiene éste, desde el planteamiento de Améry, para la concepción de la historia centrada en las demandas de las víctimas.

\section{Nietzsche y el resentimiento}

Améry refiere como uno de sus interlocutores directos al filósofo alemán Friedrich Nietzsche. Este último exige una superación (que tal vez debería decirse anulación) del resentimiento como posibilidad única para afirmar la "voluntad de vida" y la "voluntad de poder".

La visión de Nietzsche representa una perspectiva de vencedores sobre vencidos, los cuales habrían logrado su victoria con base en la fuerza y el sometimiento; con base en la "voluntad de poder" y la "afirmación de la vida": "ofender, violentar, despojar, aniquilar no pueden ser naturalmente 'injustos desde el momento en que la vida actúa esencialmente, es decir, en sus funciones básicas, ofendiendo, violando, despojando, aniquilando, y no se le puede pensar absoluto sin ese carácter'"' (2006a, p. 98).

La transvaloración que hicieron los "esclavos" tergiversó los conceptos del bien y del mal. A través de un peculiar análisis filológico acusa el que estos conceptos fueron re-definidos, a través del resentimiento, por un grupo de hombres débiles, vulgares, plebeyos, y bajos. Éstos, los judíos, denuncia Nietzsche, fueron los que invirtieron la identificación aristocrática de los valores en la siguiente acepción: "bueno= noble $=$ poderoso $=$ bello $=$ feliz $=$ amado de Dios" $(2006 a$, p. 46). En otras palabras, originaron una transvaloración de los valores, valga la redundancia, de los fuertes, nobles, aristócratas. La transvaloración dio las siguientes significaciones: “ilos miserables son los buenos; los que sufren, los indigentes, los enfermos, los deformes son también los únicos piadosos, los únicos benditos de Dios, únicamente para ellos existe la bienaventuranza". En su contraparte, lo malo designa a "nobles y violentos, quienes son para toda la eternidad, los malvados, los crueles, 
los lascivos, los insaciables, los ateos, y vosotros seréis también enteramente los desventurados, ¡los malditos y condenados!'” (2006a, p. 46).

La transvaloración de los valores se origina en una rebelión de esclavos; una rebelión de aquellos que habían sido sometidos por los fuertes, los engendradores de valores, los afirmadores de la voluntad de poder. Los esclavos, hechos astutos por su condición misma de esclavos, comenzaron a trabajar en la parte más profunda de la cultura; comenzaron a trabajar sobre los estratos más profundos, básicos y más desprotegidos de la psique; comenzaron a trabajar con el inconsciente y con los instintos a través del concepto de la culpa. En la base de esta moral se encuentra el re-sentimiento. Éste es el que engendrará los valores en un acto re-activo: "el resentimiento de aquellos seres a quienes le está vedada la auténtica reacción, la reacción de la acción, y que se desquitan únicamente con una venganza imaginaria" (2006a, p. 50).

Si bien, para Nietzsche la Voluntad de Poder es afirmativa, ésta no implica la abolición de lo negativo sino en una transformación de esto en una manera de ser afirmativa. Esto es afirmar lo negativo de la vida, a través de la voluntad de poder, en un sentido destructivo y propositivo. Justamente lo contrario de aquellos que hacen los buenos de la moral que aspirarían a un mundo bueno y verdadero sin contradicciones (Castrillo, 2006, p. 56; Nietzsche, 2006b, p. 281).

Una idea fundamental en la interpretación nietzscheana es la confrontación entre las fuerzas activas y las fuerzas re-activas. Las fuerzas activas son fuerzas de afirmación "aspiran a dominar, a imponerse, a extenderse, a afirmar la diferencia, a separarse, a decir sí a la vida". En su contraparte, las fuerzas re-activas "tienden a garantizar su conservación, a reprimirse y negar la vida" (Vanioff, 2015, p. 3).

El ser humano resentido es un ser re-activo. No es propositivo; no es afirmativo, es receloso y vengativo. Es un ser inteligente y astuto. Es un ser que niega y criminaliza lo mundano porque a éste se le ha quitado el derecho a ese mundo. Crea un mundo que sí le pertenece y al que sí tiene acceso: el mundo de lo imaginario; el mundo de las ideas. Es un mundo en el que él es el dueño y jerarca. 
Con este "nuevo" eje cultural el ser humano es puesto a disposición del re-sentimiento y de lo re-activo (Nietzsche, 2006a, p. 56).

El "hombre" domesticado queda así degradado. Es un gusano hombre. Así, éste modelo se afirma como sentido de la historia humana en la idea del hombre superior.

La consecuencia de una moral basada en la pena, consecuencia de lo re-activo, es el aumento del temor, así como el dominio y control de los instintos. Los instintos fuero dominado y reprimidos. La consecuencia de esto, dice Nietzsche, es que al ser reprimidos se volvieron hacia dentro. Se generó la interiorización del ser humano que desembocó en la rebelión de los instintos contra él mismo: "La enemistad, la crueldad, el placer en la persecución, en la agresión, en el cambio, en la destrucción -todo esto vuelto contra el poseedor de tales instintos: ése es el origen de la 'mala conciencia'"' (Nietzsche, 2006a, p. 109).

La conciencia es re-activa; es constructora de ideales negativos. Nietzsche habla de que el sentimiento de deuda, de culpa, genera en grado supremo temor al antepasado al grado de que éste es "transfigurado en un dios".

Así, Dios es la figura del temor, de la deuda, del verdugo, de la eternidad y de la pena. Con Dios nacen también los ideales del mundo que son ideales hostiles a la vida. Son ideales ascéticos. El ideal ascético es aquel que niega y reprime los instintos; aquel que para a la voluntad de poder; aquel que alaba al mundo ideal; aquel que genera espiritualidad sobre la corporalidad; aquel que genera la creencia en un mundo por encima del mundo mundano.

Nietzsche resume el ideal ascético en tres palabras: pobreza, humildad, castidad. El sacrificio y el dolor son los purificantes que son bien recibidos para dar acceso a otro mundo. Es, a fin de cuentas, un re-sentimiento y éste no es más que odio, "una voluntad de la nada, una aversión contra la vida, un rechazo de los presupuestos más fundamentales de la vida, pero es, y no deja de ser, iuna voluntad!" (Nietzsche, 2006a, p. 205).

La idea del resentimiento en el análisis genealógico que Nietzsche hace sobre la moral es de suma importancia ya que éste es donde se apuntala la construcción de la moral judeocristiana occidental. El re-sentimiento es la vuelta al sentimiento. Es un volver al sentimiento, pero ya 
mediado por la conciencia y desarmado de su potencia activa y afirmativa de la vida. Está ya transformado en re-acción. Así, el resentimiento se presenta como una incapacidad para olvidar porque el sentimiento fue reprimido y marcó indeleblemente el interior, la sique, y la corporalidad de la persona.

El resentimiento crea memoria y la memoria crea resentimiento. La memoria se forja a través del dolor.

Dice Deleuze (2000, p. 36), refiriendo a la filosofía de Nietzsche, que el resentimiento es reacción porque se transforma en algo sentido que se ejerce sobre lo activo, relacionando esto último con la vergüenza. Así, ésta es separada de su potencia y de capacidad de poder. El resentimiento se vuelve creador de valores en una dinámica que, al ser negado el acto, se busca resarcir a través de una venganza imaginaria.

Así pues, acorde con el análisis de Nietzsche el re-sentimiento es un valor re-activo que enferma al ser humano y que le niega su posibilidad y sus capacidades constructivas, creativas, propositivas en contra de la voluntad de poder; de la voluntad de vida.

\section{La psique y el resentimiento: una lectura psicoanalítica}

Améry se enfrenta también contra las explicaciones psicológicas. El resentimiento en las explicaciones psicológicas se conceptualiza como detonante de psicopatologías y la intervención psicológica busca, justamente, superar y remediar esas psicopatologías. Améry se rebela contra el discurso psicológico que busca una cicatrización de la herida a través del paso del tiempo y de la terapia de sanación que quiera apagar y adormecer los sentimientos. En lugar de reprimir o sublimar su rencor rechaza "toda componenda para vivir es falsa paz consigo mismo y con los demás" (Marrades, 2004, p. 226).

La terapia psicoanalítica, específicamente, busca desanudar el malestar psíquico y corporal que producen las experiencias traumáticas a partir del análisis y la comprensión de las experiencias vivenciales pasadas con el fin de poder lograr, de algún modo, la cura (el bienestar) de trastornos psicológicos que dificultan en menor o mayor medida la vida psicológica y social del ser humano. 
Para el psicoanálisis el pasado no es pasado muerto. El pasado es y está presente en cada acto y en cada emoción. El pasado está indisociablemente unido al presente de por vida.

Améry se acerca al discurso psicoanalítico en cuanto a su finalidad. Justamente la exigencia que su alegato busca es encontrar una forma de recuperar algo, lo que pueda ser recuperable, de lo perdido y de lo arrebatado. Ese proceso, en términos de Améry, no refiere a un ejercicio puramente introspectivo. Requiere de un proceso material (intersubjetivo) que implica la presencia de un discurso de un otro y que ese otro reconozca la exigencia ética del discurso propio. La recuperación de ninguna forma puede ser completa, aunque sí hay una forma de restitución ética y moral. Esa se encuentra en la otredad.

El reproche al psicoanálisis es en cuanto a la conceptualización de la dolencia psíquica. La experiencia límite escapa a toda conceptualización y a la sistematización, y con esto, escapa en un sentido pleno a la comprensión y a la explicación. El análisis, en su conceptualización y en su valoración moral implícita, implica una reducción de sentido vivencial. El dolor es dolor y no otra cosa. Efectivamente, la experiencia traumática tiene que objetivizarse para encontrar una forma de lidiar con ella. Se objetiviza con la palabra en el intento de comunicación de la vivencia. Para poder presentarse como una experiencia intersubjetiva y hacer la demanda es necesaria su referencia objetiva. Es necesaria dicha objetivación porque la posibilidad de vivir con el recuerdo de esa experiencia y con sus secuelas depende de la demanda ética del reconocimiento intersubjetivo. Sigmund Freud en su teoría psicoanalítica señalaba que los seres vivos reaccionamos a una serie de estímulos. Esos estímulos son tanto internos como externos. Una forma de esos estímulos son las pulsiones. Son estímulos humanos específicos para lo psíquico que se diferencian de otro tipo de estímulos que originan una reacción fisiológica (Freud, 2003a, p. 114).

Así, el estímulo pulsional proviene del "mundo interior" del propio organismo. Estos estímulos actúan como fuerzas constantes ya que actúan desde el interior. Debido a esto, a que son estímulos internos que no pueden eliminarse o satisfacerse o cumplirse, plantean exigencias diferentes a las de una reacción fisiológica. 
Freud plantea una serie de términos a partir de los cuales se conceptualizan teóricamente las pulsiones: esfuerzo, meta, objeto y fuente de la pulsión.

El esfuerzo se refiere al factor motor y a la suma de fuerzas que las pulsiones exigen. La meta se refiere al punto de satisfacción o punto de cancelación de la pulsión. El objeto se refiere al medio para alcanzar la satisfacción pulsional. La fuente se refiere al proceso somático, interior a un órgano o a una parte del cuerpo en que el estímulo es representado en la vida anímica (Freud, 2003a, pp. 117-118).

Freud distingue dos tipos de pulsiones: las yoicas o de autoconservación y las pulsiones sexuales. Las pulsiones yoicas están encaminadas a la conservación del individuo y las sexuales a la conservación de la especie. Sin embargo, estos dos tipos de pulsiones coexisten y se autoimplican. Para las pulsiones yoicas lo sexual es una de sus funciones y tiene como necesidad la satisfacción sexual. Las pulsiones sexuales asumen al individuo como un "apéndice temporario y transitorio del plasma germinal, cuasi-inmortal, que le fue confiado por [el proceso de] la generación" (Freud, 2003a, p. 120).

Así, las pulsiones sexuales tienen como meta "el logro del placer orgánico" que sólo después de haber alcanzado una síntesis cumplida entran al servicio de la función de reproducción (Freud, 2003a, p. 121).

Las pulsiones buscan como meta ser satisfechas. Para su satisfacción "no directa" pueden adquirir varios destinos: el trastorno hacia lo contrario, la vuelta hacia la propia persona, la represión y la sublimación.

El trastorno hacia lo contrario implica la transformación de la pulsión de actividad a pasividad o de su contenido (amor $\rightarrow$ odio). La vuelta hacia la persona propia implica que esa energía pulsional al no poder ser satisfecha se vuelca hacia el propio individuo transformado su carácter de activa a pasiva (masoquismo) (Freud, 2003a, p. 122).

En la vuelta hacia la propia la meta no cambia. Cambia la vía del objeto. La vía de satisfacción pulsional es la propia persona en la que se descarga la energía de la pulsión. La meta pulsional que era activa se pasa a una pasiva. 
La represión tiene el objetivo de evitar el displacer cuando una pulsión no puede ser satisfecha. La represión acontece en el inconsciente. La pulsión obtiene una representante y una representación psíquica. A esta representación de la pulsión se le niega su admisión en lo consiente. Si algo logra traspasar al consciente, a través de los procesos el "representante de la pulsión" es obligado a desaparecer (Freud, 2003b, p. 148).

Una etapa segunda de la represión consiste en negar el acceso a lo consciente a todos los "retoños psíquicos" derivados de la agencia representante reprimida. Freud señala que la represión consiste en un "esfuerzo de dar caza" a todas la representaciones ligadas o derivadas a la representación pulsional reprimida.

La energía pulsional al no poder ser dirigida y lograda en su meta, produce efectos sintomáticos que pueden ser diversos. Pueden ir de las fobias, a las neurosis o a las histerias que son formas de lidiar con esas energías pulsionales reprimidas.

La represión tiene como origen al ideal del yo, es decir, al deber ser: "Así debes ser" y "Así no te es lícito ser" (Freud, 2001, p. 35). En la represión se ponen en juego las dinámicas del gasto y conservación energéticas bajo la ecuación placer-displacer.

Por su parte, la sublimación consiste en que la pulsión busca de otra manera su satisfacción sexual. Es decir, hay una desviación respecto de lo sexual (Freud, 2003c, p. 91). En este proceso hay una idealización del objeto. La exigencia de la sublimación es dada, al igual que en los procesos represivos, por el ideal del yo que adquiere estatuto de conciencia moral. La sublimación, entonces, implicaría la satisfacción de objeto (pulsional) y del cumplimiento del ideal del yo.

Ahora bien, acorde con lo expuesto, las pulsiones buscarían como meta primordial ser satisfechas (principio de placer). Freud encuentra un fenómeno psíquico que supone la repetición simbólica de una vivencia displacentera que le denomina “compulsión de repetición” (Freud, 2004b).

Para desentrañar este proceso Freud asume que la temporalidad de los procesos psíquicos inconsciente es diferente a la de la vida consciente. Para él "los procesos anímicos inconscientes son 
en sí 'atemporales'” (Freud, 2004b, p. 28). Esto quiere decir que su permanencia es constante y, digamos, "eterna".

Señala Freud que existen ciertas excitaciones externas (vivencias) que son tan fuertes que logran traspasar los mecanismos de defensa anti-excitación que los organismos poseen para su supervivencia, y dejan una impronta en los estratos profundos de la psique. A estas excitaciones les llama traumáticas. Ante esta situación la estructura psíquica tiene la necesidad de dominar ese estímulo para poder conducirlo a su desarme, en la medida de lo posible, ya que es un peligro y evitar, así, el displacer.

Para tal objetivo se produce una "contrainvestidura" a partir de la cual los demás sistemas psíquicos se empobrecen ocasionando un rebajamiento o parálisis de las demás operaciones psíquicas.

Así, los mecanismos psíquicos de defensa buscan recuperar el dominio sobre el estímulo para mantenerlo controlado y reducir su peligrosidad. Freud había señalado en su obra $L a$ interpretación de los sueños que los sueños representaban el cumplimiento de los deseos. (Freud, 2004a, p. 142 y ss). Sin embargo, posteriormente encuentra que no a todos los sueños se les puede aplicar esta afirmación. Dice que en los sueños de los neuróticos las situaciones traumáticas se repiten; conducen nuevamente al enfermo a la situación en la que vivió la experiencia traumática, lo que contravendría la tesis sobre el sueño y el cumplimiento del deseo. Los sueños de los neuróticos, dice Freud, buscan recuperar el dominio sobre el estímulo por medio del desarrollo de una angustia cuya omisión causó la neurosis (Freud, 2004b., p. 31).

La compulsión a la repetición es un mecanismo psíquico de defensa que busca reducir la excitación que produce la experiencia traumática a través del control de la vivencia. La repetición incansable de dicha vivencia implicaría el deseo de volver a un estado anterior al acontecimiento perturbador. En este sentido Freud define la pulsión como

[...] un esfuerzo, inherente a lo orgánico vivo, de reproducción de un estado anterior que lo vivo debió resignar bajo el influjo de fuerzas perturbadoras externas; sería una suerte de 
elasticidad orgánica o, si se quiere, la exteriorización de la inercia en la vida orgánica. (Freud, 2004b, p. 36).

Al final, en la hipótesis de Freud, las pulsiones orgánicas buscan volver al estado anterior a toda excitación, al estado de lo inanimado. Esto parecería un contrasentido cuando se piensa en términos evolutivos. Es decir, se supone, desde la teoría evolutiva, que hay un desarrollo progresivo en las especies vivas. La cuestión es cómo podría ser posible esto si hay una fuerza intrínseca en los organismos vivos que tiende a la regresión. Sin embargo, los estímulos exteriores a los que han estado expuestos los seres vivos han dejado variaciones en cada especie que han sido preservadas en la repetición. Dice Freud:

Si nos es lícito admitir como experiencia sin excepciones que todo lo vivo muere, regresa a lo inorgánico, por razones internas, no podemos decir otra cosa que esto: La meta de toda vida es la muerte; y, retrospectivamente: Lo inanimado estuvo ahí antes que lo vivo. (Freud, 2004b, p. 38).

Si bien la meta de toda la vida sería la muerte, el organismo buscaría morir a su manera de manera que lucha con todas sus energías contra los peligros que le harían alcanzar su meta por el camino más corto. Hay una contraposición entre pulsiones. Un grupo de pulsiones lanzan al organismo hacia adelante y terminar con la vida. Otro grupo de pulsiones tienden a lanzar hacia atrás para retroceder desde cierto punto y prolongar lo más posible la duración de la vida.

Freud caracteriza a las pulsiones yoicas como esas pulsiones que tienden a la regresión al estado inanimado lo más inmediatamente posible (pulsiones de muerte). En su contraparte las pulsiones sexuales son las que tienden a la preservación de la especie a través de la "fusión de dos células germinales diferenciada". Éstas son las pulsiones de vida (Freud, 2004b, p. 43).

En el planteamiento de Freud hay una contraposición interna de las energías pulsionales que buscan la circularidad (guiada por las pulsiones de muerte o las pulsiones yoicas) y las que, digamos, buscan cierta linealidad (guiada por las pulsiones de vida o las pulsiones libidinales) en los procesos 
vitales y vivenciales. En la propuesta nietzscheana la contraposición también está presente. Tiene la forma de lo activo en contra de lo re-activo. Así, el nudo se presenta en una dicotomía entre contrarios con fines, medios e intencionalidades que parecería, en gran medida, antitéticos; pero que, sin embargo, puede decirse, funcionan teleológicamente con intenciones análogas: cumplir los dictámenes de las energías pulsionales.

Lo circular o repetitivo está ligado a una experiencia vivencial traumática. Funciona como eje a partir del cual se orienta el movimiento circular con el que giran las energías pulsionales que ponen en peligro la vida del propio sujeto y de los demás sujetos por la orientación que éstas pueden tener en términos de los procesos psíquicos sadomasoquistas.

Señala Luis Kancyper que el resentimiento, que se origina a partir de las experiencias traumáticas de los individuos, se presenta como un fenómeno psíquico estrechamente ligado a la memoria en el que, a diferencia, de los procesos psíquicos de represión en los que el sujeto es capaz de "desalojar" acontecimientos traumáticos, los procesos traumáticos se vuelven intolerables ya que se presentan como "cuerpos extraños" que están aislados del "curso asociativo con el resto del yo". Es decir, debido a que no encuentran una significación simbólica no pueden ser reprimidos y permanecen escindidos y fuera de la "circulación psíquica” no pudiendo, por esto, evolucionar (Kancyper, 2005, p. 85).

El resentimiento se configura en la memoria. Las experiencias traumáticas pueden representar a la psique un alto costo grado energético, ya que al activar mecanismos de defensa realiza una disociación entre el hecho ocurrido y el efecto que produjo a través de la represión. Los síntomas remplazan al hecho. Requiere olvidar el hecho ya que es más fácil vivir con el síntoma que con el hecho doloroso.

Freud descubre que en el caso de las histerias (y también en los estados psíquicos normales), los síntomas neuróticos desaparecían en la medida en que se conseguía despertar con luminosidad el recuerdo del suceso traumático, convocando al mismo tiempo el afecto producido. De manera contraria, cuando el recuerdo no se lograba acompañar del afecto el procedimiento analítico era ineficaz (Freud, 2002, p. 32). De la conclusión que saca Freud de su análisis se desprende que puede 
haber una disociación entre el recuerdo y el afecto de éste. Es decir, a partir de los mecanismos de represión hay un cambio de investiduras de objeto que produce ese desfase. La posible cura analítica consistiría en tratar de hacer que haya nuevamente una correspondencia entre ambos.

La pérdida de afectividad de los recuerdos depende de varios factores. Lo que está en juego en esta pérdida es si frente al suceso afectante hubo una reacción enérgica o no (Freud, 2002, p. 34). La reacción consistiría en los reflejos voluntarios e involuntarios que hacen que se descarguen los afectos. Ésta puede ir desde el llanto hasta la venganza. De manera que si hubo una reacción en escala suficiente el afecto desaparece. Si la reacción fue sofocada, el afecto permanece conectado con el recuerdo. Uno de los mecanismos psíquicos normales para rectificar el efecto de la sofocación de la reacción es la abreacción. Ésta consiste en la descarga de emociones y afectos ligados a un recuerdo a través de diferentes medios que pueden ir desde la expresión oral, la expresión gestual o la expresión física. En el caso de los fenómenos histéricos los recuerdos de las vivencias traumáticas están ausentes de la memoria más no así las afecciones que las mismas originaron.

Otro de los motivos que señala Freud como originantes del olvido de un recuerdo tiene que ver con los estados psíquicos en que sobrevinieron las vivencias. Éstos pueden ser el terror o estados psíquicos anormales (Freud, 1992, p. 36). Ambas clases de condiciones pueden conjugarse.

Señala Freud que las afecciones de situaciones traumáticas que se vuelven patógenas están tan frescas debido a que se les ha denegado un desgate normal por abreacción o por la reproducción en estados de asociación desinhibida.

Así, la intención de la terapia analítica es la de poder corregir la disociación de la representación no abreaccionada con su afecto para introducirla en la conciencia para que pueda, de esta manera, ser desfogada de su energía pulsional:

[La psicoterapia] Cancela la acción eficiente de la representación originalmente no abreaccionada, porque permite a su afecto estrangulado el decurso a través del decir, y la lleva hasta su rectificación asociativa al introducirla en la conciencia normal (en estado de 
hipnosis ligera) o al cancelarla por sugestión médica, como ocurre en el sonambulismo con amnesia" (Freud, 2002, p. 42).

\section{Jean Améry y el resentimiento}

Améry cita La genealogía de la moral de Nietzsche:

[...] el resentimiento determina a aquellos seres, a los que la verdadera reacción, la del acto, les está vedada, que sólo se resarcen con una venganza imaginaria... El hombre del resentimiento no es ni franco ni ingenuo, ni íntegro ni recto consigo mismo. Su alma mira de reojo; su espíritu ama los escondrijos y las puertas falsas, todo lo oculto le interesa como su mundo, su hospicio, consuelo. (2004, p. 147).

Como se ha presentado, la referencia que hace Nietzsche sobre el resentimiento es sumamente negativa y corresponde a una forma de de valor reactivo que niega la posibilidad de creación cultural y que va en contra de la afirmación de la vida.

La réplica que hace Améry a Nietzsche, y a todas las formas de psicologismo, parte de la legitimidad que pertenece y le es inherente al padecimiento vivencial de un hecho determinado.

El resentimiento adquiere su legitimidad en la medida en que es un sentimiento vuelto a sentir que remite a lo irreductible de una experiencia fenoménica. Remite a eso que no puede ser teorizado o conceptualizado: "Hablo como una víctima y escudriño mis resentimientos. [...] Mi objetivo es describir la condición subjetiva de víctima. Mi contribución consiste en el análisis introspectivo del resentimiento" (Améry, 2004, pp. 140-142).

Améry arremete contra los moralistas (Nietzsche) y contra los psicologístas (incluido el psicoanálisis) en su intento de teorizar el estado psíquico del resentimiento: "Ios primeros la juzgan [a la condición subjetiva de la víctima resentida] una mácula, los segundos la consideran una suerte de morbo" (Améry, 2004, p. 142). 
¿Por qué el sentimiento (llamado re-sentimiento) de la víctima se vuelve un referente de autoridad para designar un fenómeno moral?

Primero. Había señalado Freud que la temporalidad de una vivencia en el interior de la psique no es la misma que la temporalidad lineal de una vivencia espacio-temporal de la psique en un ámbito de una experiencia vivencial. De manera que la experiencia vivencial individual tiene su propia presencia fenoménica. Así, para la experiencia subjetiva, ésta no consiste en un "resentimiento". Es un sentimiento que se origina a partir de una experiencia originaria presente, constante y latente. Remite a una vivencia que se carga de una energía emotiva y sensorial inmediata presente.

El resentimiento del que habla Améry refiere a una experiencia primaria que antecede a toda elaboración, comprensión o explicación conceptual. Teorizar dicha experiencia tiene el peligro, inevitable, de quitarle la carga subjetiva que es de donde el resentimiento tiene su fuerza de demanda ética. Si bien, es cierto que toda experiencia subjetiva en su objetivación a través del lenguaje pierde cierta carga y potencialidad emotiva, dicha objetivación en la voz propia de la víctima conserva la legitimidad y autoridad inherente de quien vivió un acontecimiento como víctima.

El lugar desde donde Améry habla es el lugar de la víctima que ha sufrido una vejación extrema. Fue sobreviviente de los campos de exterminio nazi; fue sobreviviente de Auschwitz. En sus palabras, su declaración no es susceptible de ser teorizada como una experiencia moralizante ya que esto supondría vaciar la experiencia de subjetividad desligándola de sí mismo:

En Auschwitz no nos hemos hecho más sabios, siempre que por sabiduría se entienda un saber positivo sobre el mundo: nada de cuanto comprendimos en el interior del campo no habría sido posible comprenderlo también fuera: nada se nos transformó en una guía práctica. Tampoco en el campo hemos llegado a ser más 'profundos', suponiendo que la fatal profundidad sea una dimensión espiritual definible. Salta a la vista, creo, que en Auschwitz ni siquiera nos hemos hecho mejores, más humanos, más filantrópicos ni más maduros moralmente. No se puede ser testigo de los crímenes del hombre deshumanizado sin 
cuestionar todas las nociones sobre la dignidad innata del ser humano. Del campo salimos desnudos, expoliados, vacíos, desorientados -y tuvo que pasar mucho tiempo antes de que reaprendiésemos el lenguaje cotidiano de la libertad. Por ciento, todavía hoy lo contamos con malestar y sin verdadera confianza en su validez. (2004, p. 79).

¿Cuál es el significado del testimonio directo de Auschwitz? La pregunta es compleja y llena de aporías. Por un lado, Auschwitz es un lugar sin referencias en la historia de la humanidad (Cf. Reyes Mate, 200a). Lo es tal vez por la naturaleza del crimen (Pilatowsky, 2007).

Entonces, ¿cómo encontrar referencias para hablar de lo acontecido ahí? Y dentro de esta pregunta ¿en qué lugar queda el testimonio de la victima de este acontecimiento? y aún más ¿cómo puede ser comunicable lo acontecido en Auschwitz? Georgio Agamben, por ejemplo, hace una reflexión sobre el testigo y el caso del musulmán. ${ }^{3}$ Una de las tesis de Agamben es que el significado de Auschwitz sólo es posible en la relación dialéctica entre el testigo y el musulmán en la que la figura del musulmán representa el silencio absoluto (Reyes, 2003a, p. 9).

Agamben hace la comparación de la mirada del musulmán con aquel que ha visto a la Gorgona. En la mitología griega quien veía a la Gorgona quedaba petrificado y, por consecuencia, moría. Por tanto, la Gorgona no tenía rostro conocido porque todo aquel que hubiera podido mirarlo y dar testimonio de éste, habría muerto con la imposibilidad de dar cuenta de éste.

Así, para Agamben el musulmán es "el que ha visto a la Gorgona" (2009, p. 55). Esta designación, explica Agamben, refiere no a algo que está en el campo o que acontece en éste; algo que el musulmán habría visto. Designa más bien:

[...] la imposibilidad de ver de quien está en el campo, de quien en el campo "ha tocado fondo" y se ha convertido en no-hombre. El musulmán no ha visto nada, no ha conocido nada, salvo la imposibilidad de conocer y ver. (2009, p. 55).

\footnotetext{
3 En la referencia del mismo Améry el musulmán en el lenguaje del campo era el "prisionero que había abandonado cualquier esperanza y había sido abandonado por sus compañeros, no poseía ya un estado de conocimiento que le permitiera comparar entre bien y mal, nobleza y bajeza, espiritualidad y no espiritualidad. Era un cadáver ambulante, un haz de funciones físicas ya en agonía. Debemos, pues, por dolorosa que nos parezca la elección, excluirle de nuestra consideración". (Citado por Agamben, 2009, p. 41)
} 
Así, el musulmán se vuelve una figura central en lo decible e indecible de Auschwitz. En el fondo de lo "no humano" no hay nada que ver. Por esta razón, afirma Agamben, la Gorgona, el musulmán y el que testimonia, representan la imposibilidad de ver y así, de expresar lo vivido y lo visto.

Reyes Mate afirma que el silencio de Auschwitz sólo puede aparecer al final de un discurso que es un diálogo entre la palabra del testigo y la mudez del musulmán:

Sin la palabra del primero el silencio del segundo sería in-significativo; pero la palabra del testigo no puede agotar toda la verdad, sino que remite al silencio del musulmán, silencio que obliga a la palabra del testigo, al conocimiento que tengamos, a no clausurarle. (Reyes, 2003a, p. 10).

El último testimonio de Auschwitz, que no se tiene, es el de quien que ha visto a la Gorgona y no ha vuelto para contarlo. Por eso dice Reyes Mate que el silencio de Auschwitz se expresa en el límite de la relación dialéctica entre el testimonio y lo indecible. El testigo que testimonia, ningún musulmán, es quien puede hacerlo porque no sufrió la suerte de millones de seres humanos en su camino de inhumanidad. Su palabra es privilegiada (Reyes, 2003b, p. 237).

El testimonio de Améry sobre lo ocurrido es posterior, en cuanto a la relevancia, al sentimiento que dicho acontecimiento le origina. Améry no quiere hacer una narración de lo que vivió en los campos de exterminio nazi más que en la medida en que describen su resentimiento. Su resentimiento no requiere una justificación porque es la subjetividad de la experiencia la que lo origina. Su escrito no es testimonial como lo podrían ser otros escritos que buscan recuperar una enseñanza moral sobre Auschwitz como los que escribieron Primo Levi o Robert Antelme, por ejemplo. Justamente una de las tesis del texto de Améry es que su resentimiento no necesita una justificación (recuperar la lección moral de Auschwitz). Requerirle una justificación sería banalizar su vivencia.

La memoria y el resentimiento, que se engendra en ésta, y que describe Améry, son testimonios de un hecho acontecido que marcó de manera indeleble la vida y la muerte de una y de 
millones de personas. Son la exigencia del reconocimiento del agravio perpetrado y sufrido; refieren al sentimiento del sufrimiento que busca ser reconocido y reivindicado; que es legítimo y que es: “Exige absurdamente que lo irreversible debe revertirse, que lo acontecido debe cancelarse" (2004, p. 149).

El resentimiento es sentimiento vivo: no es pasado y no es futuro. Es presente: "No se me escapa que el sentido del tiempo de quien es presa del resentimiento se encuentra distorsionado, trastocado, si se prefiere, pues desea algo doblemente imposible: desandar lo ya vivido y borrar lo sucedido" (2004, p. 149).

El resentimiento tiene todo su valor en la subjetividad porque el dolor y la tortura son subjetivos. Esa subjetividad le concede su valor moral. Dice Améry:

Sólo yo estaba, y estoy [sobre las torturas a que fue sometido] en posesión de la verdad moral de los golpes que aún hoy me resuenan en el cráneo, y por tanto, me siento más legitimado a juzgar, no sólo respecto a los ejecutores, sino también a la sociedad que sólo piensa en su supervivencia. (2004, p. 151).

El resentimiento de Améry se vuelve una demanda ética y moral porque es la exigencia a los victimarios del reconocimiento del crimen por ellos perpetrados: "Mis resentimientos existen con el objetivo de que el delito adquiera realidad moral para el criminal, con el objeto de que se vea obligado a enfrentar la verdad de su crimen" (2004, p. 151).

El paso del tiempo no debilita, no borra y no minimiza el hecho de la vejación. El pasado no es pasado. El tiempo no cura. La herida psíquica, que crea y describe la conciencia del hecho, no sana como una herida fisiológica. La herida psíquica, en su carácter moral, exige la suspensión del tiempo lineal para hacer responsable al criminal de su crimen.

La coartada del criminal es el tiempo progresivo. Éste apuesta al olvido en el paso del tiempo; a la degradación del recuerdo y a la denigración de la subjetividad en pos de la superación del crimen por parte de la víctima. 
El resentimiento de la víctima es la piedra en el zapato del criminal y de quienes lo han arropado por su participación directa o indirecta en su crimen. La víctima es incomoda porque señala de manera directa la culpabilidad del victimario y le exige responsabilidad.

Améry analiza el concepto de "culpa colectiva". Señala que hay que manejar este concepto de manera cuidadosa. ¿A quiénes concierne el hecho y el agravio perpetrado? Es claro que hay una responsabilidad individual por los actos que no puede ser soslayada ni diluida en una colectividad. Hacer eso implicaría banalizar la culpa y el agravio. Sin embargo, todo criminal realiza su acto en un contexto cultural y simbólico en el que éste adquiere significados y fundamentos. En su legítima subjetividad la victima adquiere una especie de derecho de señalar culpables. Estos culpables son los que en mayor o menor medida permitieron o solaparon el crimen. Éstos van desde los que dieron los medios para cometer el crimen de manera individual hasta a los que callaron su señalamiento. Esa "culpa colectiva" exige también un reconocimiento del crimen y el asumir la responsabilidad por el mismo en la medida de la participación.

Pero también esa "culpa colectiva" pesa sobre aquellos que se empeñan en ocultar, borrar u olvidar el crimen. Mucho de esa culpa colectiva se juega en la memoria histórica porque mientras hay la exigencia de victimas del crimen el paso del tiempo debe estar negado:

La generación de los exterminadores, de los constructores de cámaras de gas, de los generales siempre dispuestos a estampar su firma, sumisos a su Führer, envejecen con dignidad. Acusar a los jóvenes, empero, sería absolutamente inhumano y a todas luces antihistórico. ¿Qué relación habría de de tener un estudiante de veinte años, crecido al socaire de la nueva democracia alemana, con las acciones de sus padres y abuelos? Sólo un odio acumulado, bárbaro, veterotestamentario, podría soportarse su lastre y pretender cargarlo sobre las espaldas de la inocente juventud alemana. (2004, p. 158).

Entonces ¿en qué medida el correspondería la culpa a generaciones nuevas de un crimen perpetrado por sus antecesores? Dice Améry: “Es razonable aceptar que los jóvenes están libres de culpa individual y de la suma de las culpas individuales que dan lugar a la culpa colectiva". Sin 
embargo, en la medida en que las nuevas generaciones asumen una tradición cultural y un legado histórico sin hacer referencia a las victimas sobre las que se construyó o que vejó esa tradición y legado:

[...] la juventud alemana no puede apelar a Goethe, Mörike o a Freiherr von Stein y olvidarse de Blunck, Wilhelm Schäfer y Herich Himmler. No es legítimo reclamar para sí la tradición nacional cuando es honorable y negarla cuando, encarnando el olvido de todo sentido del honor, proscribe a un adversario tal vez imaginario y seguramente indefenso. Si ser alemán significa reclamarse descendiente de Matthias Claudius, entonces también entraña sin duda alguna incluir en el árbol genealógico a Hermann Claudius, el poeta oficial del partido nacional socialista. Thomas Mann era consciente de este hecho cuando en su ensayo "Alemania y los alemanes" escribió: "Para un espíritu nacido alemán es imposible afirmar: yo represento la Alemania buena, justa, noble, sin mancha... nada de lo que es he contado sobre Alemania procede de un saber ajeno, frio, distante; todo anida en mí, todo lo he experimentado en mi mismo". (2004, p. 159).

Walter Benjamin habla de la necesidad de peinar la historia a contrapelo (2006, p. 68). Esto quiere decir que la historia, el concepto de la historia, no se debe construir sólo sobre las bases de "logros" de una sociedad o una cultura. Es necesario leer la historia a través del dolor, del sufrimiento y de las injusticias sobre las que se erigen esos "logros"; sobre las bases reales de la cultura y la sociedad. Esto implica desarrollar una memoria histórica que permita recuperar esos hechos e insertarlos en la tradición cultural desde la que se grita la grandeza de la misma. El resentimiento de la víctima se vuelve el arma contra el olvido y la concreción de la injusticia.

El resentimiento puede ser todo lo que han dicho Nietzsche o Freud que es. Pero eso no importa. Es secundario. La presencia y la exigencia de la víctima desarman en un dos por tres la fanfarronería sofistica de Nietzsche, así como la imponente construcción teórica de Freud. Desarma la pretensión de objetividad. Hay que entender aquí este último término como des-subjetivación.

El resentimiento se convierte en un imperativo ético sobre el que es necesario plantear y replantear la relación intersubjetiva de los unos con los otros que ya no puede ser la objetividad 
racional planteada por Kant. Esto porque si la ética se trata de generar elementos reflexivos que permitan una relación intersubjetiva adecuada a través del reconocimiento de otro como el yo mismo, ésta no se puede generar cuando el (rostro del) otro está fracturado y desfigurado a causa de la vejación, de la violencia, del crimen que no ha recibido la justicia digna, o que se intenta esconder, ocultar u olvidar.

Justamente la reflexión ética se hace necesaria porque existe el sufrimiento. El sufrimiento, dice José María Mardones, orienta la mirada hacia los lugares de la dominación y la opresión (2004, p. 54). Entonces, dirige la mirada hacia el reconocimiento del sufrimiento del otro, que es el agraviado. Así, la fuerza de la exigencia de justicia de la víctima es el punto de partida que permitiría de alguna forma, tal vez mínima para el tamaño del agravio, recomponer la fractura de la relación intersubjetiva. Y ésta habla a partir de su subjetividad, de su sentimiento o, como se le llama, de su resentimiento.

\section{Modernidad y progreso}

La concepción progresiva del tiempo que domina a la modernidad exige como imperativo moral el olvido y el perdón como exigencias a las víctimas para poder construir una sociedad libre, feliz, equitativa y justa (recuérdese a Nietzsche). Exige, no a través de la consecución real de justicia ante al agravio, la superación del re-sentimiento (y todo el dolor activo y pasivo que éste conlleva) a través del olvido y del perdón. Porque aceptar la demanda de la víctima supondría cuestionar los fundamentos mismos de las promesas que la modernidad y el progreso han hecho.

El escritor polaco Tadeusz Burowski, sobreviviente de Auschwitz, en un par de líneas de su relato Nuestra casa es Auschwitz enunció lo siguiente:

Los objetos sensibles no son el reflejo de ninguna idea, sino el resultado del sudor y la sangre de los hombres. Fuimos nosotros los que construimos las pirámides, los que arrancamos el mármol y las pierdas de las calzadas imperiales, fuimos nosotros los que remábamos en las galeras y arrastrábamos arados, mientras ellos escribían diálogos y 
dramas, justificaban sus intrigas con el poder, luchaban por las fronteras y las democracias. (2004, p. 49).

El progreso se levanta sobre la ruina, el sufrimiento y la barbarie. De manera que es urgente la fractura del progreso; la fractura del tiempo lineal que soporta este progreso. Urgente repensar la historia y el tiempo a partir de las claves de los oprimidos, las víctimas y los vejados para lograr ya no un continuum, sino más bien un discontinuum (Benjamin, 2008, p. 69). ${ }^{4}$

El crimen que se comente en y por el progreso abre una herida imborrable. Rompe para siempre el estado previo al crimen; rompe la condición constitutiva originaria previa. La absolución de crimen resulta imposible porque no hay forma de retornar a la condición previa. Por tanto, la restitución real es imposible. El punto es entonces en qué forma se puede generar un estado, un lugar, una situación en la que haya algún tipo de (re)conciliación a favor de la víctima para que ésta pueda, de algún modo, tener una condición que le permita seguir viviendo de la mejor manera posible.

Al progreso le urge el olvido y la superación del crimen, pero no de una forma ética intersubjetiva. Le urge que sea de una forma inmediata. El olvido se juega en la memoria y ésta, a su vez, se juega en el continum del tiempo:

No, nada resiste a esta fuerza silenciosa, continua, implacable, a esa presión verdaderamente infinita del olvido progresivo; ningún resentimiento, por obstinado que sea, aguanta ante esa mansa indiferente y de desafecto. Todo nos aconseja olvidar. La memoria,

\footnotetext{
4 Habría que señalar la tesis de que el nazismo (Auschwitz) no es resultado de una extravagancia o una anomalía en la historia del ser humano. Sino que más bien es la consecuencia de la instrumentalización plena de la razón moderna en pos del ideal ilustrado. (Cf. Levinas, 1998; Horkheimer, 2010; M. Horkheimer y T. Adorno, 2009; Reyes Mate, 2003b) El filósofo español Alberto Sucasas hace una interesante reflexión sobre los claroscuros de la modernidad en su relación con el holocausto. Si bien el autor reconoce que la modernidad ha estado acompañada por actos barbáricos, como es el caso de Auschwitz, la modernidad ha tenido una contracara que no puede no reconocerse (Sucasas, 2010, p. 21). El autor pugna por una visión crítica de la modernidad que tenga como uno de los elementos centrales su ambivalencia entre sus posibilidades constructivas y creativas, y sus posibilidades barbáricas y destructivas (que posibilitaron Auschwitz). De manera que la modernidad no debería ser desechada sin más. Las posibilidades mismas que da a la vida humana siguen siendo enormes y, a su vez, resulta uno de las formas más fuerte de contención para la caída en la barbarie. Esto siempre a la luz presente del suceso histórico de Auschwitz como referente de crítica y vigilancia.
} 
vencida de antemano, solamente puede oponer a la futurición una defensiva siempre provisional y por lo general desesperada... Un día u otro, a la larga, el olvido oceánico sumergirá todos los rencores en su grisalla niveladora: así es como las arenas del desierto acaban sepultando ciudades muertas y civilizaciones difuntas, y así es como la acumulación de siglos y de milenios envolverá, a lo sumo, en la inmensidad de la nada los crímenes inexplicables y las glorias imperecederas. (Jankelevitch, 1999, p. 26).

Ante el "imparable" continum de la historia se presenta el resentimiento para denunciar sobre qué rieles se desliza ese progreso. El resentimiento, como memoria, es la posibilidad de la salvación:

La memoria es salvación del pasado y del presente. Salvación del pasado porque gracias a la nueva luz podemos traer al presente aspectos desconocidos del pasado; y del presente, porque gracias a esa presencia el presente puede saltar sobre su propia sombra, es decir, puede liberarse de la cadena causal que lo trajo al mundo. (Reyes, 2009, pp. 108-109).

\section{Conclusiones}

Jean Améry sebe que con su resentimiento se enfrenta a toda la historia y que, como lo señalaba Jankelevitch (1999), el tiempo y el olvido son implacables. Sabe que con su resentimiento se enfrenta a toda una tradición cultural que solapa el crimen desprestigiando y objetivizando a la víctima. Le dice a Nietzsche y a Scheler ${ }^{5}$ que no deberían preocuparse por su "moral de esclavos", la de él, Hans Maier, y de los resentidos, porque sabe que no triunfará (2004, p. 166). Sabe que la historia es la historia de los vencedores; que su resentimiento es la piedra en el zapato. Sabe que

\footnotetext{
5 Para Max Scheler el resentimiento está ligado con el rencor ("enojo retenido") (1938, p. 11). Para Scheler es una "autointoxicación psíquica". El resentimiento se forma en un impulso de venganza y ésta, a su vez, se origina en una vivencia de impotencia, de la debilidad. Esas fuerzas represivas que son, en palabras de Scheler, "el sentimiento de impotencia, una acusada conciencia de "no poder», enlazada con un fuerte y penoso sentimiento de depresión; también son fuerzas represivas el temor, la angustia y el pánico entre la tendencia a expresarse y a obrar en la dirección de afectos" (1938, p. 58). La condición necesaria para que el resentimiento surja es que haya un sentimiento de impotencia de traducir sentimientos en afectividad. Así, el resentimiento es para los "siervos y dominados, a los que arrastran y suplican, vanamente, contra el aguijón de una autoridad" (1938, p. 20).
} 
hay una intención objetivadora de la memoria, esa que despoja su viveza al dolor de las personas y que requiere del olvido para seguir viviendo.

El resentimiento se vuelve un elemento ético que imposibilita objetivar y anular la experiencia de la vivencia del sufrimiento y, como tal, representa la confrontación directa contra la intención objetivizadora que nulifica la carga subjetiva vivencial del sufrimiento que es la que puede volcarse como categoría ética real.

Améry reivindica al resentimiento como una demanda ética en contra de las concepciones psicológicas y de los estudios morales. El resentimiento, no es temporalmente un segundo sentimiento. Es un sentimiento de fuerza viva y presente a la cual no le vale la superación del pasado. Le vale el cumplimento de la justicia a través del reconocimiento por parte del victimario de lo que hizo, así como sus esfuerzos para evitar que vuelva a suceder algo semejante. No se trata de recomponer porque no hay forma.

La categoría del resentimiento funciona como ancla de la memoria y la memoria como posibilidad de la consecución de justicia individual, social e histórica. El resentimiento irrita tanto a la sociedad y a la cultura porque señalan sus puntos oscuros; señala la violencia sobre las que se erige; apunta a sus secretos ocultos.

El resentimiento genera una batalla contra la marcha del progreso y en ésta la víctima es la clave y la voz que tiene el estatuto más alto y legítimo. Al hacer esto genera la posibilidad de una relación intersubjetiva que esté basada en un supuesto de eticidad. La víctima no está obligada a olvidar ni a perdonar. Tiene el derecho a odiar y a generar con este odio un resentimiento.

También da la posibilidad para hacer una reconstrucción de la historia que señale a los responsables y exija a sus herederos reconocimiento. Es decir, hacer una historia desde los vejados por el proceso civilizatorio que se ha construido sobre tanto dolor e injusticias.

\section{Referencias}

Agamben, G. (2009). Lo que queda de Auschwitz. El archivo y el testigo. Homo Sacer III, Barcelona: Pre-textos. 
Améry, J. (2004). Más allá de la culpa y la expiación, Valencia: Pre-textos.

Arendt, H. (2009). Eichman en Jerusalén, Barcelona: DeBolsillo.

Benjamin, W. (2006). Ensayos escogidos, México: Ediciones Coyoacán.

Bejamin, W. (2008): Tesis sobre la historia y otros fragmentos, México: ITACA, UACM.

Borowsky, T. (2004). Nuestro hogar es Auschwitz, Barcelona: Alba Editorial.

Castrillo, D. (2006): “Prólogo”, en: La voluntad de poder, Nietzsche (aut.), Madrid, Edaf.

Deleuze, G. (2000). Nietzsche, Madrid: Arena Libros.

Drews, P. (2012), “Memoria y resentimiento en Jean Améry”. Obtenido el 21 de julio de 2019, de La caverna de Platón. Espacio de Filosofía:

www.lacavernadeplaton.com/articulosbis/amery1112.htm\# ftnref11.

Freud, S. y J. Brauer, (1893). Sobre el mecanismo psíquico de fenómenos histéricos: comunicación preliminar, en: Obras completas, II, Buenos Aires, Amorrortu, 1992, pp. 27-44.

Freud, S. (1923). El yo y el ello, en: Obras completas, XIX, Buenos Aires: Amorortu, 2001, pp. 1-66.

Freud, S. (1923). Sobre el mecanismo psíquico de fenómenos histéricos, en: Obras completas, III, Buenos Aires, Amorrortu, 2002, pp. 25-40.

Freud, S. (1915). Pulsiones y destinos de pulsión, en: Obras completas, XIV, Buenos Aires, Amorrortu, 2003a, pp. 105-134.

Freud, S. (1915). La represión, en: Obras completas, T. 14. Buenos Aires: Amorrortu, 2003b, pp. 135152.

Freud, S. (1914). Introducción del narcisismo, en: Obras completas, XIV. Buenos Aires, Amorrortu, 2003c, pp. 65-98

Freud, S. (1899), La interpretación de los sueños, en: Obras completas, IV, Buenos Aires, Amorrortu, 2004a, pp. 1-715

Freud, S. (1920), Más allá del principio de placer, en: Obras completas, T. 18. Buenos Aires: Amorrortu, 2004b, pp. 1-136

Horkheimer, M y T. Adorno (2009). Dialéctica de la llustración. Fragmentos filosóficos, Madrid: Trotta. 
Horkheimer, M. (2010). Crítica de la Razón Instrumental: Madrid, Trotta.

Jankelevitch, V. (1999). El perdón, Barcelona: Editorial Seix Barral.

Kancyper, L. (2005). La memoria del rencor y la memoria del dolor, Intercamvis Intercambios de Psicoanálisis; núm. 10, 84-94.

Kant, I. (1991). Antología, Barcelona: Ediciones Península.

Levinas, L. (2012). Totalidad e Infinito, Salamanca: Ediciones Sígueme.

Mardones, J. (2004), Sufrimiento humano y la respuesta política. En De Bárcena, F. et al (Eds.). La autoridad del sufrimiento. Silencio de Dios y preguntas del hombre (p. 43-60), Barcelona: Anthropos Editorial.

Marrades, J. (2004). Resentimiento y verdad. Sobre la réplica de Améry a Nietzsche, Isegorías, núm. 31, 221-236.

Nietzsche, F. (2006a). La genealogía de la moral, Madrid: Alianza.

Nietzsche, F. (2006b). La voluntad de poder, Madrid: Edaf.

Pilatowsky, M. (2007). La filosofía después de Auschwitz en Latinoamérica. En M. Reyes Mate y R. Forster (Eds.), El judaísmo en Iberoamérica (p. 279-303), Barcelona: Trotta.

Reyes, M. (2003a). La singularidad del holocausto. En M. Reyes Mate (Ed.), Por los Campos de Exterminio, Barcelona: Ánthropos.

Reyes, M. (2003b). Memoria de Auschwitz. Actualidad moral y política. Madrid: Trotta.

Reyes, M. (2009). Media noche en la historia. Comentarios a las tesis de Walter Benjamin "Sobre el concepto de historia», Madrid: Trotta.

Scheler, M. (1938). El resentimiento en la moral, Buenos Aires: Espasa- Calpe.

Sucasas, A. (2010). Holocausto y modernidad. Tres tesis críticas, Nuestra Memoria, núm. 33, pp. 1534.

Galibert, U. (2002). Diccionario de psicología, México: Siglo XXI.

Vanioff, K. (2015). Consideraciones sobre la memoria y el olvido en la filosofía de Friedrich Nietzsche, Nuevo Itinerario. Revista Digital de Filosofía, vol. 10, núm. 10, pp. 1-24. 